\title{
Biological implications of longevity in dairy cows: 1. Changes in feed intake, feeding behavior, and digestion with age
}

\author{
F. GrandI, ${ }^{*}$ S. P. Luzi, ${ }^{*}$ M. Furger,† J. O. Zeitz,† F. Leiber,§ S. Ortmann,\# M. Clauss,॥ M. Kreuzer, ${ }^{* 1}$ \\ and A. Schwarm* \\ ${ }^{*}$ ETH Zurich, Institute of Agricultural Sciences, Universitaetstrasse 2, 8092 Zurich, Switzerland \\ †Agricultural Education and Advisory Centre Plantahof, Kantonsstrasse 17, 7302 Landquart, Switzerland \\ łJustus-Liebig-University Gießen, Institute of Animal Nutrition and Nutritional Physiology, Heinrich-Buff-Ring 26-32, 35392 Gießen, Germany \\ §Research Institute of Organic Agriculture (FiBL), PO Box 219, 5070 Frick, Switzerland \\ \#Leibniz Institute for Zoo and Wildlife Research Berlin, Alfred-Kowalke-Strasse 17, 10315 Berlin, Germany \\ IIUniversity of Zurich, Vetsuisse Faculty, Clinic for Zoo Animals, Exotic Pets and Wildlife, Winterthurerstrasse 260, 8057 Zurich, Switzerland
}

\begin{abstract}
Milk production strategies focusing on longevity and limited use of concentrate are receiving increasing attention. To evaluate such strategies, knowledge of the development with age of animal characteristics, particularly digestion, is indispensable. We therefore investigated the development of feed intake, chewing activity, and digestion in 30 lactating Brown Swiss cows (876-3,648 d old) and 12 heifers (199-778 d old). We also studied whether age effects were exhibited differently in animals selected from herds subjected for $11 \mathrm{yr}$ either to a forage-only or to a forage-concentrate feeding regimen. Forages consisted of grass hay (the only feed for heifers), corn silage, and grass pellets. Measurements lasted for $8 \mathrm{~d}$, where amounts and composition of feeds, feces, and milk were recorded and analyzed. Ruminal $\mathrm{pH}$ data and eating and rumination activity were assessed by $\mathrm{pH}$ sensors put into the rumen and halter-mounted noseband sensors. The mean retention time of feed particles was assessed using Cr-mordanted fiber and data were used to calculate dry matter gut fill. Data were subjected to regression analyses with age and feeding regimen as explanatory variables, and body weight, milk yield, and proportion of hay in forage as covariates. This allowed separating age-related changes of body weight and milk yield from independent age effects and correcting for differences in preference for individual forages. In cows, organic matter intake increased with age (from slightly below to above $20 \mathrm{~kg} / \mathrm{d}$ ), as did mean retention time and gut fill. Digestibility of organic matter did not show a clear age dependency, but fiber digestibility had a maximum in cows of around 4 to $6 \mathrm{yr}$ of age. Ruminal $\mathrm{pH}$ and
\end{abstract}

Received August 15, 2015.

Accepted January 12, 2016

${ }^{1}$ Corresponding author: michael.kreuzer@inw.agrl.ethz.ch absolute eating and rumination times did not vary with cow age. Young and old cows chewed regurgitated boluses more intensively (60-70 times) than middle-aged cows (about 50 times). Effects of feeding regimen were small, except for fiber intake and rumination time per unit of intake, owing to the different fiber content of the diets. No significant interactions between age and feeding regimen were found. Heifers spent more time eating and ruminating per unit of feed than cows, which resulted in a high fiber digestibility. Irrespective of the feeding regimen tested, older cows maintained intake and digestion efficiency with longer retention times and chewing rumination boluses more intensively. The results support efforts to extend the length of productive life in dairy cows.

Key words: lactation number, digestibility, digesta passage time, ruminal $\mathrm{pH}$, rumination

\section{INTRODUCTION}

Milk production by dairy cows has been globally intensified by favoring genotypes with high daily milk yields (Miglior et al., 2005). These cows need proportionately fewer nutrients for maintenance and are particularly efficient in transforming nutrients into milk (Flachowsky and Brade, 2007; Prendiville et al., 2009), a phenomenon called "dilution of maintenance" (Capper and Bauman, 2013). The disadvantage of this highyield strategy is that increasing amounts of concentrate are required, resulting in resource-intensive production that is in direct competition with human food supply (Oltjen and Beckett, 1996; Kiefer et al., 2014). Furthermore, the average number of parities per cow in high-yield strategies is decreasing or, at best, stable at a low level (e.g., 2.6 to 3.3 in the United States and Germany; Hare et al., 2006a; Knaus, 2009; Rohde et al., 2009). Even though involuntary culling due to different diseases or poor reproductive performance is 
more frequent than voluntary selection, a substantial proportion of the herd is culled exclusively to accelerate breeding progress for performance (Hadley et al., 2006; Pinedo et al., 2010). A short productive lifetime of cows requires additional rearing of replacements for culled cows, which is a rather unproductive period, as only meat from the culled cows is contributing to food production. Rearing takes at least 2 yr (Hare et al., 2006b), which is equivalent to almost half of the entire lifetime of dairy cows under current conditions. Therefore, increasing the longevity of cows enhances the dilution of the nonproductive stage by a longer productive lifespan.

To develop strategies for sustainable dairy production based on an increased length of productive life, knowledge about nutrient intake and digestion characteristics of animals at higher ages is indispensable. Results from Hayirli et al. (2002) and Jensen et al. (2015) suggest that feed intake capacity in dairy cattle increases with age. For other herbivorous species, such as deer, the capacity of the rumen-reticulum was reported to proportionately increase with age along with ruminal retention time (Veiberg et al., 2009; Duarte et al., 2011). Graham (1980) showed an increase in nutrient digestibility from weaner lambs to 6-yr-old sheep. Pérez-Barbería and Gordon (1998) stated in their review that improved chewing ability and modified chewing behavior can compensate for decreasing tooth effectiveness during lifetime; both influence the degree of feed comminution and, thus, feed degradability. Tooth effectiveness and feeding behavior have also been used to explain higher feed intake rates in mature compared with young cows (Pérez-Barbería and Gordon, 1998; Boudon et al., 2009). Furthermore, differences in diet composition (particularly fiber and its digestibility; Riaz et al., 2014) could result in different age trends in intake and digestion. Most of the recent literature on age effects in cattle is limited to the distinction between primiparous and multiparous cows (e.g., Maekawa et al., 2002b; Wathes et al., 2007; Devries et al., 2011) or groupings of cows across several lactations (e.g., >3, Fall et al., 2008; >4, Keene et al., 2004). In addition, cows in experiments are usually only chosen from a restricted age range, and thus older cows are often deliberately omitted.

Therefore, the objective of the present study was to determine if any changes in digestion occurred with age in dairy cattle continuously distributed over a large age range. Age effects were tested in 2 different feeding regimens (zero concentrate diet vs. control diet including concentrate). As a first step, nutrient intakes as well as feeding and digestion characteristics in heifers and cows of different ages $(0.5-10 \mathrm{yr})$ were investigated. Three hypotheses were tested. (1) Dairy cattle increase their intake capacity with age, which allows them to increase intake without compromising ruminal fermentation conditions, digesta retention, and digestibility. (2) As chewing efficiency changes with age, cattle show a curvilinear development of chewing and rumination activity. (3) The age effect depends on the feeding regimen. The age-related changes were expected to go beyond the more obvious ones occurring from the transition from the heifer state (nonlactating) to primiparous cows and the subsequent transition from primiparous to multiparous cows. As a second step, methane emissions and efficiency were investigated as decisive criteria for environmental sustainability of longevity strategies in dairy production (described in Grandl et al., 2016).

\section{MATERIALS AND METHODS}

\section{Animals and Feeding}

The experiment, carried out from October 2013 to February 2014, was approved by the veterinary office of the Swiss canton of Zurich (149/2013).

Thirty lactating cows and 12 heifers of the Brown Swiss breed were selected from the 2 herds of the Agricultural Education and Advisory Centre Plantahof (Landquart, Switzerland). These herds were managed with different feeding regimens since 2003, and replacement was exclusively done within feeding regimen. Concentrate was completely omitted in one feeding regimen (0-CONC). In the other feeding regimen, the diet for the lactating cows included concentrate $(5 \mathrm{~kg} / \mathrm{d}$ per cow, 2 types either rich in energy or in protein were given in a ratio of 3:2). This was referred to as a control feeding regimen (CTRL), as this is a representative feeding practice for higher-yielding dairy cows. Year-round, animals in both feeding regimens received similar forages (hay, fresh grass or grass silage, corn silage, and pellets made from artificially dried grass, supplemented with $\mathrm{NaCl}$ and minerals). Cows were kept in a tiestall barn and treated identically. Sires used for AI were the same in both feeding regimens. All heifers of both feeding regimens were raised together on the same forage-only diet. After parturition they were allocated to the respective feeding regimen into which they had been born.

The animals (including the nonlactating heifers) were selected to achieve a maximum age spectrum and were balanced for feeding regimens and DIM. The age range covered a span from 199 to 3,648 d for CTRL and 310 to $3,640 \mathrm{~d}$ for 0 -CONC (weaned calves to cows in the seventh lactation; details given in Table 1). The experiment was conducted in 7 subsequent runs during which 6 animals were subjected to the experimental procedures in parallel. The procedures lasted for a total of 
Table 1. Description of the experimental animals selected from the control (CTRL) and the zero concentrate $(0-\mathrm{CONC})$ feeding regimen (ranges or means $\pm \mathrm{SD}$ )

\begin{tabular}{lcc}
\hline & \multicolumn{2}{c}{ Feeding regimen } \\
\cline { 2 - 3 } Item & CTRL & 0 -CONC \\
\hline Cows (n) & 15 & 15 \\
Age range (d) & $876-3,648$ & $1,086-3,640$ \\
Number of cows & 4 & 3 \\
Lactation 1 & 2 & 4 \\
Lactation 2 & 2 & 3 \\
Lactation 3 & 3 & 1 \\
Lactation 4 & 2 & 1 \\
Lactation 5 & 0 & 2 \\
Lactation 6 & 2 & 1 \\
Lactation 7 & $619-781$ & $579-738$ \\
BW range (kg) & $710 \pm 53$ & $666 \pm 51$ \\
Mean BW (kg) & $127 \pm 57$ & $111 \pm 68$ \\
DIM & $42.5 \pm 7.5$ & 7 \\
Milk yield ${ }^{1}(\mathrm{~kg} / \mathrm{d})$ & 5 & $310-778$ \\
Heifers (n) & $199-729$ & $309-565$ \\
Age range (d) & $258-514$ & $389 \pm 105$ \\
BW range (kg) & $419 \pm 102$ & \\
Mean BW (kg) & &
\end{tabular}

$\overline{{ }^{1} \text { As measured in last monthly milk performance recording before the }}$ beginning of the experiment.

$11 \mathrm{~d}$ for each animal. On the first day, the animals were moved in pairs for $3 \mathrm{~d}$ to respiration chambers situated at an experimental station (approximately $160 \mathrm{~km}$ driving distance; Grandl et al., 2016). Afterward, the animals returned to the tiestall barn for an 8-d sampling period during which various traits describing in- take, feeding behavior, and digestion were investigated. The experimental diets for the lactating animals were identical to the common winter diet used in the respective feeding regimens (Table 2). Therefore, a specific dietary adaptation was not needed for the cows before the start of the experiment. Heifers usually received leftovers from the cows. As these are often variable in composition, during the experiment the heifers received a hay-only diet (same hay as cows), to which they were adapted for $10 \mathrm{~d}$.

During the experiment, feeding and milking took place along with the normal routine applied to all cows. Periods of feeding were from 0300 to $0800 \mathrm{~h}$ and from 1415 to $1800 \mathrm{~h}$, where hay was provided at ad libitum access in portions of 1 to $2 \mathrm{~kg}$ (as fed). At the end of each feeding period, a larger portion of hay was offered to last until the next feeding period started. Corn silage was given once per feeding period after the first portion of hay. Grass pellets and concentrate were given in 2 and 4 portions per feeding period, respectively. During evening feeding, $50 \mathrm{~g} / \mathrm{d}$ of $\mathrm{NaCl}$ and $100 \mathrm{~g} / \mathrm{d}$ of a vitamin-mineral supplement were provided. The latter contained (per kilogram) $100 \mathrm{~g}$ of Ca, $80 \mathrm{~g}$ of P, $20 \mathrm{~g}$ of $\mathrm{Na}, 75 \mathrm{~g}$ of $\mathrm{Mg}, 750 \mathrm{mg}$ of $\mathrm{Cu}, 4 \mathrm{~g}$ of $\mathrm{Zn}, 3 \mathrm{~g}$ of $\mathrm{Mn}, 30 \mathrm{mg}$ of I, $20 \mathrm{mg}$ of Co, $40 \mathrm{mg}$ of Se, $1 \mathrm{~g}$ of S, $1,000,000 \mathrm{IU}$ of vitamin $\mathrm{A}, 200,000 \mathrm{IU}$ of vitamin $\mathrm{D}_{3}$, $2,400 \mathrm{IU}$ of vitamin $\mathrm{E}$, and $100 \mathrm{mg}$ of biotin. Leftovers were removed before each new feeding period, separated into hay and corn silage (concentrate and grass pellets

Table 2. Nutrient contents of the experimental feeds, amounts of respective feeds offered per cow, and realized average intake of the these feeds (DM basis) in the control (CTRL) and the zero concentrate (0-CONC) feeding regimen

\begin{tabular}{|c|c|c|c|c|c|c|}
\hline Item & Subset & \multicolumn{5}{|c|}{ Diet component } \\
\hline \multirow{3}{*}{ Nutrients (\% of DM) } & $\mathrm{OM}$ & 90.6 & 96.6 & 88.9 & 93.8 & 93.8 \\
\hline & $\mathrm{CP}$ & 12.3 & 7.1 & 18.2 & 23.5 & 44.4 \\
\hline & $\mathrm{EE}^{1}$ & 1.88 & 3.22 & 4.07 & 6.79 & 6.36 \\
\hline \multicolumn{7}{|l|}{$\begin{array}{l}\text { Amount offered (kg } \\
\text { of } \mathrm{DM} / \mathrm{d} \text { ) }\end{array}$} \\
\hline & CTRL & ad libitum & 10.9 & 2.7 & 2.7 & 1.8 \\
\hline & $0-\mathrm{CONC}$ & ad libitum & 8.8 & 4.6 & - & - \\
\hline & Heifers & ad libitum & - & - & - & - \\
\hline Realized DMI $(\mathrm{kg} / \mathrm{d})$ & Heifers & $8.05 \pm 0.452^{2}$ & - & - & - & - \\
\hline
\end{tabular}


were completely eaten), and weighed. The animals had permanent access to water. The cows were milked at 0315 and $1500 \mathrm{~h}$.

Recording of $B W$ and ECM Yield. Body weight was measured on a pallet scale on the first day of the 8-d collection period. During the collection period, milk yield was recorded at each milking using a mechanical milk meter (Tru-Test Limited, Auckland, New Zealand). From each milking, Bronopol-conserved samples were collected and analyzed for fat, protein, and lactose by a Fourier transform infrared spectrophotometer (MilkoScan FT6000, Foss, Hillerød, Denmark) at the Swiss routine milk analysis laboratory (Suisselab AG, Zollikofen, Switzerland). The ECM was calculated based on the Agroscope (2015) equation as

$$
\begin{gathered}
\operatorname{ECM}(\mathrm{kg})=\text { milk }(\mathrm{kg}) \times[0.38 \times \text { fat }(\%) \\
+0.24 \times \text { protein }(\%)+0.17 \times \text { lactose }(\%)] / 3.14 .
\end{gathered}
$$

Body weight and ECM yield were used as covariates in the analyses of the feeding and digestion traits in the present article; their development with age is given in Grandl et al. (2016).

Assessment of Eating and Ruminating Behavior. The chewing activity of all animals was monitored with noseband sensors (MSR Electronics, Seuzach, Switzerland; Braun et al., 2013) mounted on halters that were fitted onto the cows for 3 to $4 \mathrm{~d}$ during the 8-d sampling period. A data logger (MSR 145, MSR Electronics) recorded pressure signals from an oil-filled tube that was integrated in the noseband. The signals were evaluated by the software MSR V5.20.05 (MSR Electronics) and categorized into eating, ruminating, and other activities (such as idling, drinking, scratching, and so on). Additionally, the number of rumination boluses and chews during eating and ruminating were evaluated. Chewing activity data of 1 heifer had to be excluded from analyses because extremely low values indicated a technical failure.

Measurement of Ruminal $p H$. For continuous measurement of ruminal $\mathrm{pH}, 14$ lactating cows $(7$ per regimen; i.e., approximately every second experimental cow) were equipped with an indwelling sensor bolus (smaXtec animal care $\mathrm{GmbH}$, Graz, Austria) as described by Gasteiner et al. (2012). The selected animals were quite evenly distributed over an age spectrum from 876 to $3,562 \mathrm{~d}$. The boluses were administered orally on the day before the 8-d sampling period began. Every 10 min, ruminal $\mathrm{pH}$ was recorded and stored in an internal memory. Data for each cow were retrieved via radio transmission to a hand-held device and then transferred to a $\mathrm{PC}$, where daily averages for mean $\mathrm{pH}$ and length of times with pH below 6 or 5.8 were calculated for the 8-d period. One bolus (CTRL cow) failed to transmit reasonable data.

Preparation and Application of Digesta Passage Marker. Chromium-mordanted fiber was used as particle marker for determination of passage time. For that purpose, grass hay was dried and ground with a cutting mill to pass an $8-\mathrm{mm}$ screen. The material was then dry screened to obtain material with a particle size of between 1 and $2 \mathrm{~mm}$. These particles were mordanted according to Udén et al. (1980). Briefly, particles were soaked in a sodium lauryl sulfate solution $(20 \mathrm{~g} / \mathrm{L}$ of water, $10-15 \mathrm{~L} / \mathrm{kg}$ of hay) for $4 \mathrm{~h}$ at room temperature, thoroughly rinsed with water, washed with acetone, and dried at $60^{\circ} \mathrm{C}$. Then $100-\mathrm{g}$ particles were incubated with $33 \mathrm{~g}$ of sodium dichromate dihydrate as a mordant. After washing and treatment with ascorbic acid, the particles were dried at $65^{\circ} \mathrm{C}$. The dosage provided to the animals was approximately $0.1 \mathrm{~g}$ of particle marker per kilogram of BW. The respective amounts of marker were shaped into boluses by pressing the moistened particle markers into polyvinyl chloride tubes and freezing the tubes until application. The frozen marker boluses were uncased and administered to the animals at the beginning of the sampling period using a commercial bolus applicator.

Sampling. Hay and corn silage were sampled at the beginning and the end of each run of 6 animals. The grass pellets and the 2 concentrates were sampled twice during the entire experiment. Samples of leftovers from each animal were collected twice per day during the 8 -d collection period. The samples were immediately dried at $60^{\circ} \mathrm{C}$ to constant weight and ground to pass a 1-mm screen of either a cutting mill or centrifugal mill (concentrate) for later analyses.

During the sampling period, the entire feces were collected in polypropylene trays placed at the rear end of the tiestalls. Urine was separated from feces using urinals attached around the vulva of the cows and fixed by hook-and-loop fastener straps glued (Cyanolit 202, Panacol Elosol GmbH, Steinbach, Germany) onto the skin. Representative samples of feces proportional to the amounts excreted were taken from the trays at least twice a day and the total daily amount of excreted feces was recorded and a fixed proportion ( 0.3 and $0.6 \%$ in cows and heifers, respectively) was immediately frozen. Samples were composited per cow and collection period. Additional fecal samples (approximately $100 \mathrm{~g}$ per sampling) were drawn for the determination of the digesta passage time. On the day before the marker bolus application, 3 samples were taken. Further fecal samples were collected $4,8,12,18,22,26,30,36,42$, $46,52,58,66,74,82,90,98,106,114,126,138$, and 
$150 \mathrm{~h}$ after marker application. All fecal samples were dried at $60^{\circ} \mathrm{C}$ to a constant weight and ground through a 1-mm screen with a centrifugal mill.

Laboratory Analyses. Feeds and feces were analyzed according to standard procedures (AOAC International, 1995). For DM and total ash (method 942.05; AOAC International, 1995), a thermo-gravimetric device (model TGA-500, Leco, St. Joseph, MI) was used, for nitrogen (method 977.02; AOAC International, 1995) a C-N analyzer (model Analysator Type CN2000, Leco) was used. Crude protein was defined as $6.25 \times$ N. Ether extract was determined with a Soxhlet extraction system (model Extraktionsapparatur B-811, Büchi, Flawil, Switzerland; method 963.15, AOAC International, 1995). Fiber analyses were performed as proposed in AOAC International (1995; method 973.18) using the Fibertec System M (1020 Hot Extraction, Tecator, Flawil, Switzerland). Heat stable $\alpha$-amylase was used for NDF analysis, but not sodium sulfite (Van Soest et al., 1991). Acid detergent lignin was analyzed sequentially after the ADF step by incubating in sulfuric acid $(72 \%)$ for $3 \mathrm{~h}$. Fiber data were corrected for ash content. The $\mathrm{Cr}$ content of fecal samples and particle marker was determined using inductively coupled plasma optical emission spectrometry (Optima 8000, Perkin Elmer, Rodgau, Germany), measuring at $267.716 \mathrm{~nm}$, the element's spectral line. The Cr content of the marker was $37.3 \mathrm{~g} / \mathrm{kg}$ of DM. The Cr levels measured in the 3 predosage samples were used to correct for fecal background Cr levels in each individual animal.

\section{Calculations and Statistical Analysis}

The apparent digestibility (aD) of nutrients was calculated from the amounts ingested and those recovered in the feces. The following equation from Thielemans et al. (1978) was applied to calculate mean retention time (MRT) of the digesta in the gastrointestinal tract:

$$
\operatorname{MRT}=\frac{\sum \bar{t}_{i, i+1} C_{i} \cdot \mathrm{d} t_{i}}{\sum C_{i} \cdot \mathrm{d} t_{i}}
$$

where $\bar{t}_{i, i+1}=$ mean time (h) after application of markers of 2 subsequent samplings $i$ and $i+1$ calculated as $t_{i}+\left(t_{i+1}-t_{i}\right) / 2 ; C_{i}=$ marker content in the fecal samples voided in the interval represented by time $t_{i}$ and $t_{i-1}$; and $\mathrm{d} t_{i}=$ sampling interval (h) of the respective sample, calculated as $\left[\left(t_{i+1}-t_{i}\right)+\left(t_{i}-t_{i-1}\right)\right] / 2$.

Assuming a linear absorption of nutrients during MRT (Holleman and White, 1989), the total DM present in the gut can be calculated as

$$
\begin{gathered}
\text { Total DM in gut }(\mathrm{kg})= \\
\text { DMI }(\mathrm{kg} / \mathrm{h}) \times[1-(\mathrm{aD} \text { of } \mathrm{DM} / 2)] \times \operatorname{MRT}(\mathrm{h}) .
\end{gathered}
$$

All statistical analyses were performed with the statistical software R (R Core Team, 2015). Data were subjected to parametric regression analyses. For each trait in the cows, the best model was selected by screening all possible subsets of the following full model:

$$
\begin{gathered}
Y_{\mathrm{ijklmnop}}=\mu+\mathrm{FR}_{\mathrm{i}}+\beta_{\mathrm{j}} \mathrm{A}+\beta_{\mathrm{k}} \ln (\mathrm{A})_{\mathrm{j}}+\beta_{\mathrm{l}}(\mathrm{A} \times \mathrm{FR}) \\
+\beta_{\mathrm{m}} \ln (\mathrm{BW})+\beta_{\mathrm{n}} \mathrm{ECM}+\beta_{\mathrm{o}} \text { HayProp }+\varepsilon_{\mathrm{ijklmnop}},
\end{gathered}
$$

where $Y_{\mathrm{ijklmnop}}=$ individual observation of the respective trait; $\mu=$ overall mean; $\mathrm{FR}_{\mathrm{i}}=$ fixed effect of the feeding regimen $i ; \beta_{j \ldots o}=$ regression coefficients of the continuous fixed effects of age (A, linear and ln-transformed), of the interaction of age and feeding regimen $(\mathrm{A} \times \mathrm{FR})$, and of the covariates $\ln (\mathrm{BW}), \mathrm{ECM}$ yield, and hay proportion (HayProp) in forage; and $\varepsilon_{\mathrm{ijklmnop}}$ $=$ random residual. Age was included both as linear and ln-transformed effect to allow also for nonlinear relationships between the traits and age. Including the covariates ensured that effects of feeding regimen and age were corrected for different BW and ECM yields of the animals. Potential individual animal preferences for hay versus the other forages (especially corn silage) were accounted for by including the intake of hay as a proportion of total forage intake (hay, corn silage, and grass pellets; on a DM basis). The covariate BW was included as ln-transformed variable, as it is known that many digestion traits do not scale linearly with BW (Müller et al., 2013). All models that included age (in any transformation) and feeding regimen were ranked according to the Akaike information criterion (Akaike, 1974), modified for small sample sizes (Symonds and Moussalli, 2011) using the package glmulti (Calcagno, 2013). Models with a difference in the values of the information criterion ( $\boldsymbol{\Delta}$ AICC) of less than 2 between the best and the respective models were considered to be as good as the best model. The final model was then chosen following the parsimony rule as the one with the least number of coefficients (Symonds and Moussalli, 2011). In addition to the parsimony rule, equivalent nested models with $\triangle$ AICC of less than 2 were compared with a likelihood-ratio test for the significance of additional coefficients. Equivalent non-nested models with the same number of coefficients were compared on the basis of their coefficient of determination and the residual sum of squares. All criteria matched the results of the $\triangle$ AICC ranking and the parsimony rule as decision criterion almost perfectly. Only for OM intake the model including BW was chosen against the model 
without BW, as it is known that feed intake increases with BW (e.g., Jensen et al., 2015).

Data of the nonlactating heifers were analyzed separately applying a regression model that included feeding regimen and age as effects. The reason for the separate analysis was that potential age effects in heifers are presumed to have a different biological background compared with a potential age effect in adult cows. In heifers, it is mainly driven by the growth and development of the juvenile animal, whereas the age effect in adult cattle is expected to be related to senescence. Additionally, the diet (hay only) was different from that of the cows, and the covariates ECM yield and hay proportion used in the cow regressions were not applicable to the heifer data. This also applies to BW, which is naturally highly colinear with age in growing heifers. Given that the same diet was fed to heifers from both regimens, significant feeding regimen differences in heifers would indicate genuine effects from the $11 \mathrm{yr}$ (2003-2014) of selection within feeding regimen. However, as a significant feeding regimen effect was never present in the heifers, heifer data are presented across both feeding regimens. The medians of heifer and cow data were compared with the Wilcoxon-Mann-Whitney rank sum tests.

Adjusted means for the feeding regimens were calculated with the effects package (Fox, 2003). The figures display measured individual data points, as well as regression lines and pointwise confidence bands for heifers and for cows, where the covariates (if in the model) were held constant at their median. Furthermore, to indicate model selection uncertainty, additional regression lines were added in cases where equivalent models (i.e., $\triangle \mathrm{AICC} \leq 2$ ) were identified. Model assumptions were verified by graphically analyzing residuals for normality, independence, and homoscedasticity of the errors. Effects were considered as statistically significant at $P<0.05$ and as trends at $0.05 \leq P<0.10$.

\section{RESULTS}

\section{Nutrient Intake}

The actual diet composition of the lactating cows marginally deviated from that anticipated. In detail, the intakes of hay (provided ad libitum) and of corn silage were slightly smaller than intended for both feeding regimens (Table 2). There was no consistent age trend in realized diet composition, and hay proportion in forage was not related to age (Figure 1). When cow OM intake (OMI) was analyzed with regression and thus adjusted for the covariates, we noted no difference in OMI between the 2 feeding regimens (Table 3 ).
Regression analysis revealed a significant increase of OMI in cows with age (Table 4). Intake of OM was also positively related to ECM yield and BW (not significant for OMI), as was NDF intake. The increase of OMI lessened with age, but did not reach a maximum in the age range investigated (Figure 2a). By contrast, after an initial increase with age, NDF intake started to decline slightly with higher ages in cows (Figure $2 \mathrm{~b}$ ). Intakes of OM and NDF in the heifers increased with age, but no differences were found between the animals from the 2 feeding regimens offered the same diet. When intake was expressed per unit of BW, no age effect was observed in heifers (Figure 2c, d). Organic matter and fiber intake was smaller in heifers both in absolute values and per unit of BW $(P<0.01)$.

\section{Digesta Passage, Gut Fill, and Digestibility}

The MRT of the particulate matter did not differ between feeding regimens (Table 3). The regression analysis revealed age and all covariates as significant predictors (Table 4). The MRT increased with age (Figure 2e); the average MRT was longer in the heifers as compared with the cows $(P<0.001)$. Within heifers, no age or feeding regimen effects were noted. In cows, total gut fill did not differ between feeding regimens (Table 3). Gut fill increased significantly with age (Table 4; Figure 2f) and was also positively related to BW and hay proportion in forage (Table 4). In the heifers, gut fill was smaller $(P<0.001)$ in absolute terms, but similar to that of primiparous cows when related to BW. We found no age- and feeding regimenrelated patterns in total gut fill in heifers (Figure 2f).

The apparent digestibility of OM tended to be lower in 0-CONC compared with CTRL cows, but the feeding regimen did not affect aD of NDF (Table 3). Age did not influence aD of OM (Figure $2 \mathrm{~g}$ ) and the overall model for $\mathrm{aD}$ of $\mathrm{OM}$ was not significant $(P=0.078$, Table 4). The aD of NDF showed a curvilinear relationship with age with a peak at around 2,000 d (Figure $2 \mathrm{~h}$ ). Hay proportion in forage influenced $\mathrm{aD}$ of NDF but not of OM (Table 4). In the heifers, aD of OM was in the same range as for the cows, whereas aD of NDF was greater $(P<0.001)$ in heifers. However, the observed range in individual aD was considerably wider in heifers than in cows (Figure $2 \mathrm{~g}, \mathrm{~h}$ ). There was no relationship with either age or feeding regimen in the heifers.

\section{Ruminal $\mathrm{pH}$}

The mean ruminal $\mathrm{pH}$ and the times when the $\mathrm{pH}$ was below 6.0 or 5.8 did not differ between feeding 


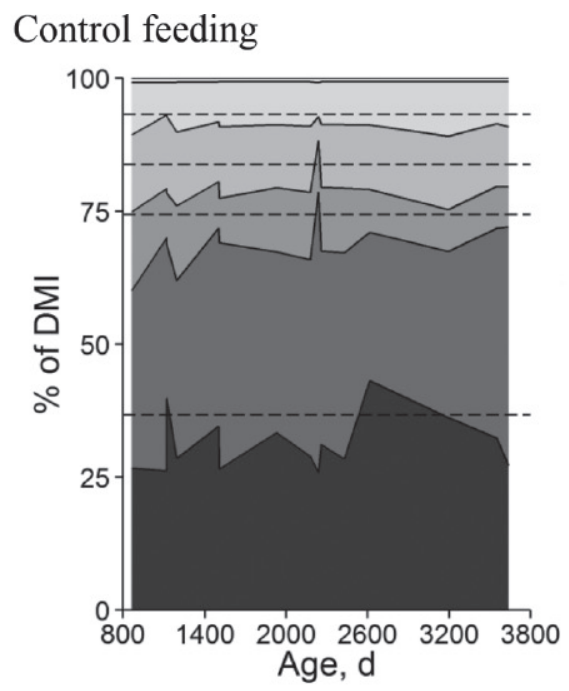

Zero concentrate feeding
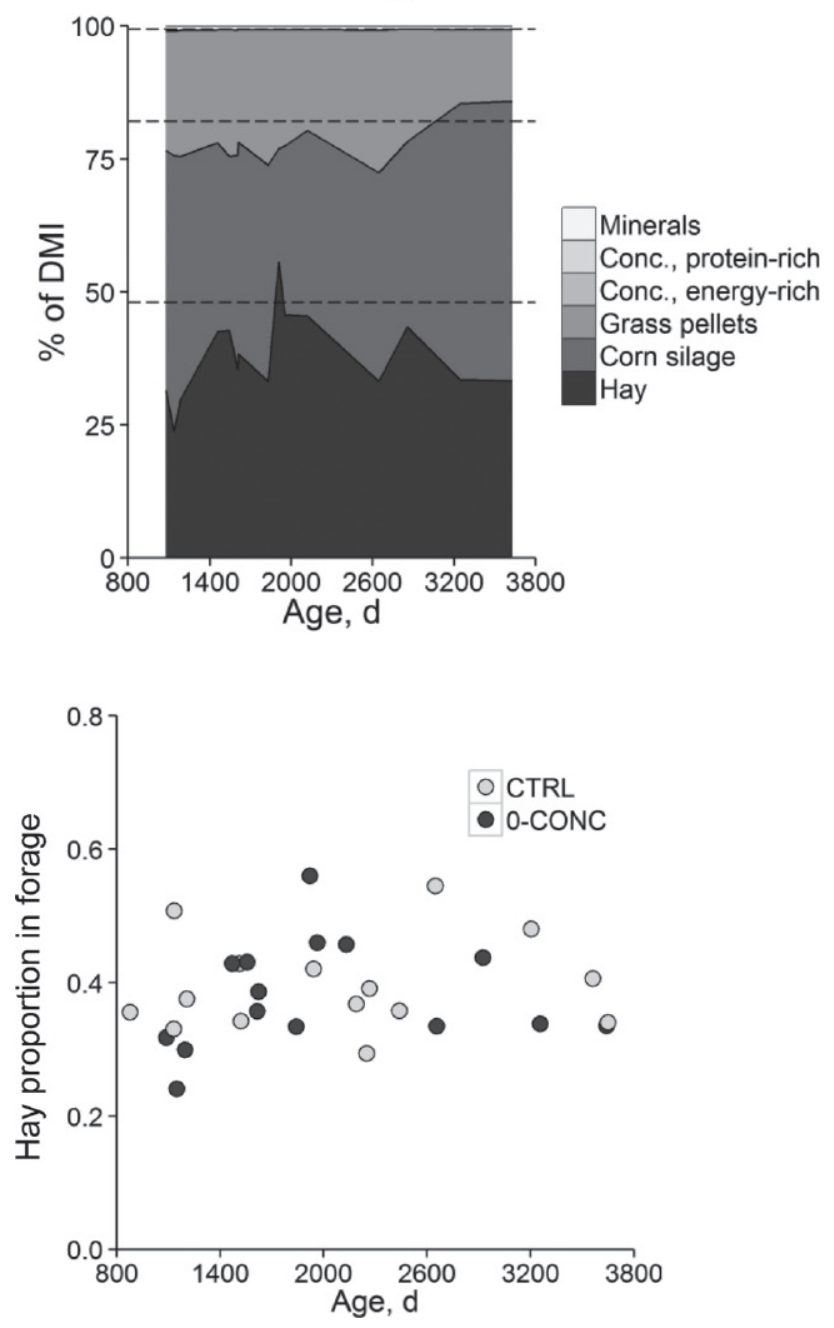

Figure 1. Actual diet composition (dashed horizontal lines = values from diet plan) for cows of different age from the control (CTRL, top) and the zero concentrate $(0-\mathrm{CONC}$, middle) feeding regimen, and hay proportion in forage consisting of hay, corn silage, and grass pellets (bottom). Conc $=$ concentrate. regimens (Table 3); age did not influence $\mathrm{pH}$ traits (Figure 2). The ECM yield was positively related to increasing mean $\mathrm{pH}$ and shorter times of $\mathrm{pH}$ being below the thresholds tested. However, the overall model fit was generally poor with all ruminal $\mathrm{pH}$ traits (Table 4). The regression models found for the $\mathrm{pH}$ traits were not significant (Table 4).

\section{Eating and Ruminating Behavior}

Absolute eating time in cows was not related to age or feeding regimen, but was significantly increased with a greater hay proportion in forage (Figure 3a; Table 4). No combination of the explanatory variables revealed a significant relationship with absolute rumination time (Table 4). No significant differences between the feeding regimens were found in any of the chewing activity traits except for rumination time per unit of DMI (Table 3). Eating time per unit of DMI and NDF intake and the number of eating chews per unit of DMI decreased with age (Figure 3b, c, g). Rumination time per kilogram of DM or NDF intake exhibited a U-shaped development with age (Figure 3e, f), with the youngest and the oldest cows spending more time ruminating per unit of intake than middle-aged cows. There were significant age effects on the number of rumination chews (Table 4, Figure 3h, i). Rumination chews per unit of DM and per bolus also showed a U-shaped development with age with most chews found in primiparous and in old cows.

The heifers expressed a greater variation in eating and rumination times than the cows when the times were related to DM or NDF intake (Figure 3). The daily eating and rumination times were in the range of the cows. Eating and rumination times per kilogram of $\mathrm{DM}$ and NDF intake remarkably decreased with age in heifers (Figure 3b, c, e, f), and the younger heifers in particular spent substantially more time for chewing compared with older heifers and cows. More eating and rumination chews per kilogram of DMI were observed in the heifers compared with the cows, and the number of chews in heifers also decreased significantly with age (Figure 3g, h). The number of chews per regurgitated bolus was in same range in heifers and cows.

\section{DISCUSSION}

To the best of our knowledge, this is the first study describing feeding and digestion characteristics of dairy cattle with age continuously distributed over a wide range and explicitly focusing on cows from herds that were adapted for a long time to 2 distinct feeding strategies. Age effects were corrected for different BW and ECM yield in cows and for individual variability 
Table 3. Intake, eating and rumination behavior, as well as digestion characteristics, of heifers and cows subjected to different feeding regimens [control (CTRL) and zero concentrate (0-CONC)], presented as arithmetic means for heifers ${ }^{1}$ and adjusted means and CI ${ }^{2}$ (in brackets) for cows

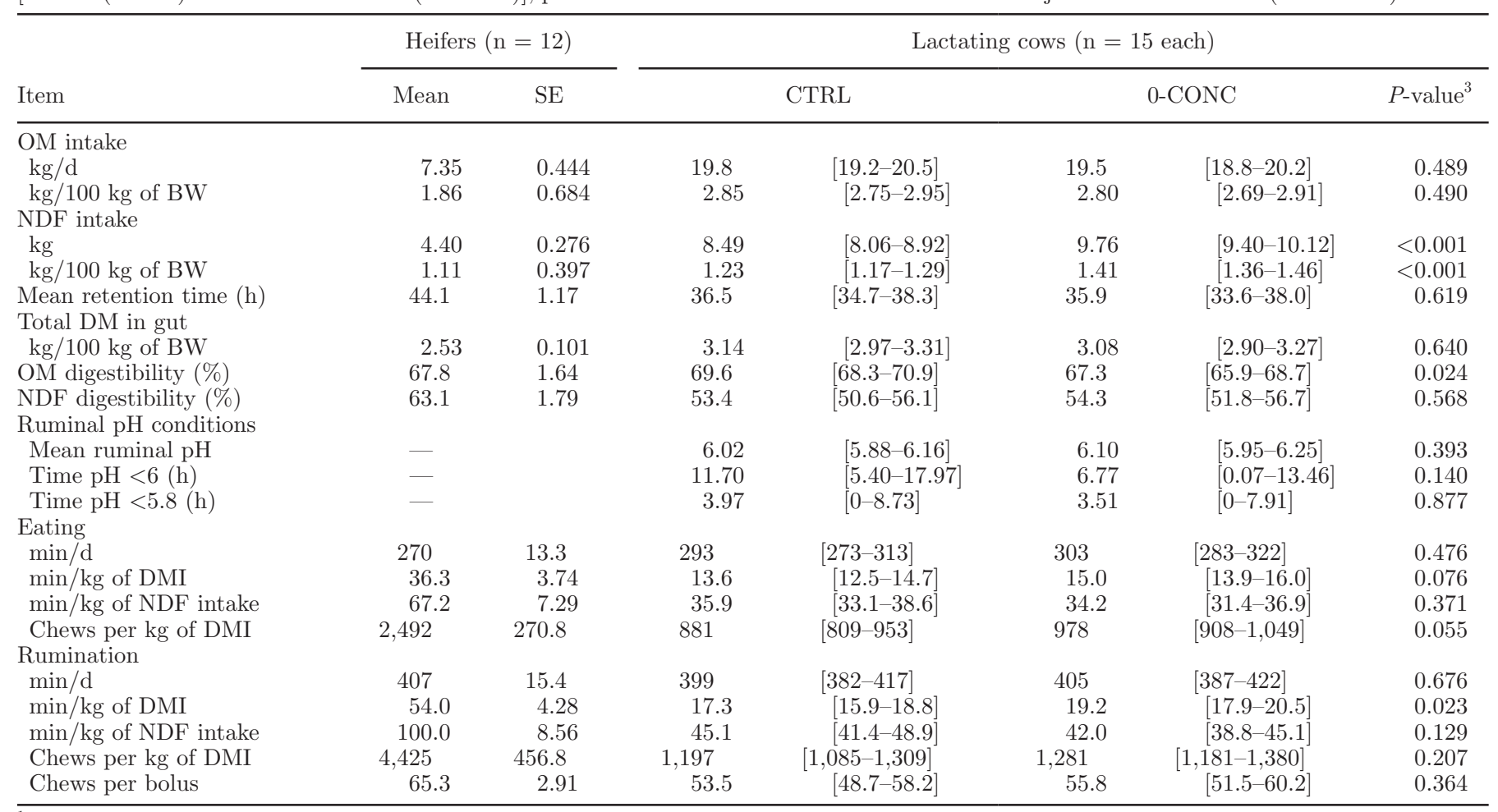

${ }^{1}$ Heifers from both feeding regimens are combined in the table, as they were fed the same diet and no differences between feeding regimens were found.

${ }^{2}$ Adjusted means (fitted values for feeding regimen levels keeping age, BW and ECM yield at their median) and $95 \%$ CI.

${ }^{3} P$-value of regression coefficient of feeding regimen.

in hay proportion in forage by including these variables as covariates in the regression analysis. A limitation of the present study is that there might have been an unknown selection effect in the group of animals used in the experiment. Animals with less favorable intake and digestion characteristics might have had a greater risk of being excluded from the herd in the course of the selection decisions made on the farm. This might have become more pronounced in cows that survived several culling decisions. Therefore, the oldest cows were potentially taken from a preselected group of animals with certain characteristics.

All age-dependent changes, such as increasing OMI, MRT, changing fiber digestibility, and changing chewing behavior described above, were similarly expressed in both feeding regimens (i.e., no significant interaction effect of age and feeding regimen was observed). This was unexpected, because dietary fiber differed and could have been more limiting for one than for the other feeding regimen. It remains an open question whether more contrasting diets would have had provoked different responses with age.

\section{Age-Dependent Changes}

Organic matter intake is a close reflection of nutrient intake; results on DMI can be found in Grandl et al. (2016). The known lower intake of primiparous compared with multiparous cows (e.g., Azizi et al., 2009; Devries et al., 2011) was also observed in the present study. However, the difference between first and later lactations was rather small compared with other studies. This might be due to the comparably high age (around 38 mo with 1 exception) of the primiparous cows, which was the result of a deliberate breeding decision of the experimental farm to fit alpine summer grazing into the breeding scheme. A relatively larger rumen capacity in mature compared with young animals (Allison, 1985; Veiberg et al., 2009) might enhance feed intake and could explain the observed increase in intake. However, NDF intake was related to age in a curvilinear fashion, showing a lower NDF intake in cows older than around 2,000 d, whereas OMI was still slightly increasing. As NDF intake is likely more limited by physical regulation than overall OMI, the observed age effects might 
Table 4. Regression coefficients for cows and their statistical significance for the analyzed target variables (all log-transformed)

\begin{tabular}{|c|c|c|c|c|c|c|c|c|c|}
\hline \multirow[b]{2}{*}{ Target variable } & \multicolumn{4}{|c|}{ Explanatory variable } & \multicolumn{3}{|c|}{ Covariate } & \multirow{2}{*}{$\begin{array}{c}\text { Adjusted } \\
\mathrm{R}^{2}\end{array}$} & \multirow{2}{*}{$\begin{array}{l}\text { Model } \\
P \text {-value }\end{array}$} \\
\hline & Feeding regimen $^{1}$ & Age & $\log$ (Age) & Age $\times$ regimen & $\log (\mathrm{BW})$ & $\mathrm{ECM}$ & Hay in forage & & \\
\hline OM intake $(\mathrm{kg} / \mathrm{d})$ & -0.361 & $-^{2}$ & $1.90^{*}$ & - & 5.92 & $0.279^{* * *}$ & - & 0.728 & $<0.001$ \\
\hline NDF intake $(\mathrm{kg} / \mathrm{d})$ & $1.27^{* * *}$ & $-1.59 \cdot 10^{-3 *}$ & $3.29^{*}$ & - & $3.75^{*}$ & $0.189^{* * *}$ & - & 0.769 & $<0.001$ \\
\hline Mean retention time $(\mathrm{h})$ & -0.734 & - & $7.96^{* * *}$ & - & $-30.5^{* *}$ & $-0.486^{*}$ & $26.0^{*}$ & 0.358 & 0.007 \\
\hline Total DM in gut $(\mathrm{kg} / 100 \mathrm{~kg}$ of $\mathrm{BW})$ & -0.0590 & - & $0.928^{* * *}$ & - & $-4.26^{* * *}$ & - & $2.42^{* *}$ & 0.546 & $<0.001$ \\
\hline OM digestibility $(\%)$ & $-2.30^{*}$ & - & 2.15 & - & $-15.7^{*}$ & - & - & 0.138 & 0.078 \\
\hline NDF digestibility (\%) & 0.875 & $-0.0138^{* *}$ & $28.8^{* *}$ & - & $-31.4^{*}$ & - & $33.7^{*}$ & 0.494 & $<0.001$ \\
\hline Mean ruminal $\mathrm{pH}$ & 0.0801 & - & $-0.250 \dagger$ & - & - & $0.0404^{*}$ & - & 0.237 & 0.153 \\
\hline Time $\mathrm{pH}<6(\mathrm{~h})$ & -4.92 & - & $11.4 \dagger$ & - & - & $-1.88^{*}$ & - & 0.259 & 0.136 \\
\hline Time $\mathrm{pH}<5.8(\mathrm{~h})$ & -0.460 & $6.93 \cdot 10^{-4}$ & - & - & - & - & - & -0.181 & 0.922 \\
\hline Eating time & & & & - & & & & & \\
\hline $\min / \mathrm{d}$ & 9.71 & - & -25.6 & - & - & - & $439^{* * *}$ & 0.407 & $<0.001$ \\
\hline $\min / \mathrm{kg}$ of DMI & $1.35 \dagger$ & - & $-3.58^{* * *}$ & - & - & - & $11.3^{*}$ & 0.376 & 0.001 \\
\hline $\mathrm{min} / \mathrm{kg}$ of NDF intake & -1.71 & - & $-6.64^{* *}$ & - & - & - & - & 0.184 & 0.024 \\
\hline Eating chews per $\mathrm{kg}$ of DMI & $97.5 \dagger$ & - & $-245^{* * *}$ & - & - & - & $789^{*}$ & 0.400 & $<0.001$ \\
\hline Rumination time & & & & - & & & & & \\
\hline $\mathrm{min} / \mathrm{d}$ & 5.12 & $-1.24 \cdot 10^{-4}$ & - & - & - & - & - & -0.067 & 0.915 \\
\hline $\mathrm{min} / \mathrm{kg}$ of DMI & $1.89^{*}$ & $5.56 \cdot 10^{-3 *}$ & $-14.8^{*}$ & - & - & - & - & 0.429 & $<0.001$ \\
\hline $\min / \mathrm{kg}$ of NDF intake & -3.20 & $0.0173^{*}$ & $-39.5^{* *}$ & - & - & -0.695 & - & 0.485 & $<0.001$ \\
\hline Rumination chews $/ \mathrm{kg}$ of DMI & 83.6 & $0.581^{* *}$ & $-1,402^{* *}$ & - & $-973 \dagger$ & - & - & 0.596 & $<0.001$ \\
\hline Rumination chews per bolus & 2.73 & $0.0229^{*}$ & $-52.4^{* *}$ & - & - & - & - & 0.241 & 0.017 \\
\hline
\end{tabular}

\footnotetext{
¿ ${ }^{1}$ Reference level is the control feeding regimen.

$\stackrel{\text { פ }}{2}$ Variable not included in the final regression model after the variable selection procedure.

을 $\quad * * * P<0.001,{ }^{* *} P<0.01, * P<0.05, \dagger P<0.10$
} 
a

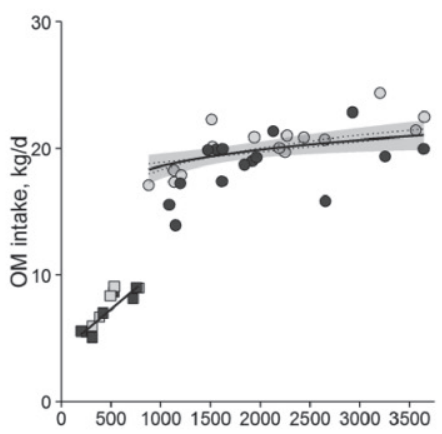

c

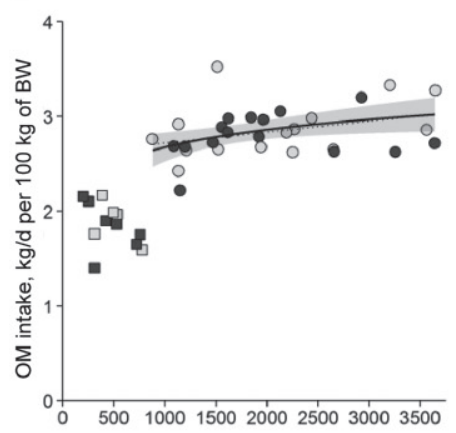

f

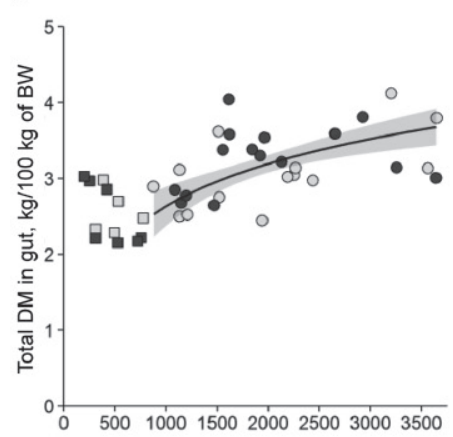

i

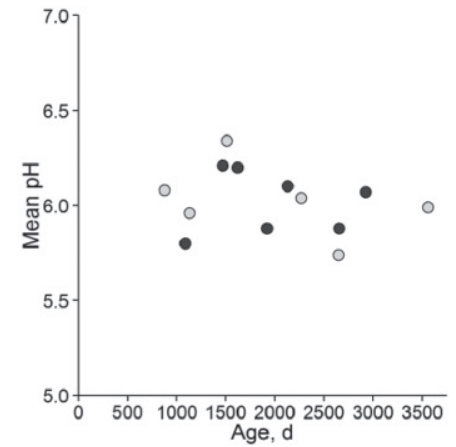

b

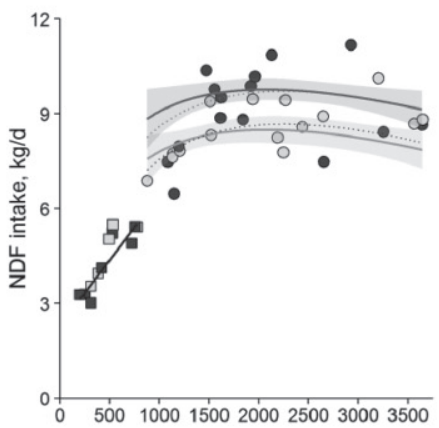

d

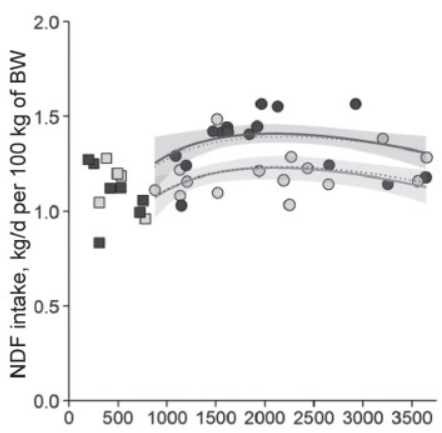

e

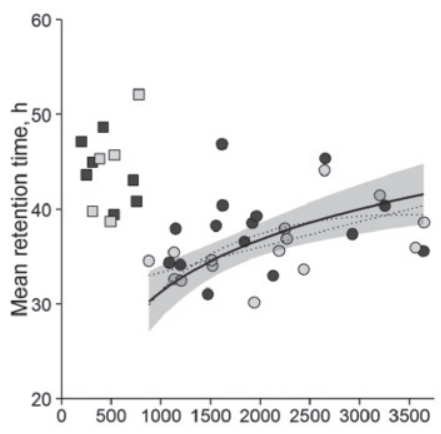

h<smiles>C=C</smiles>
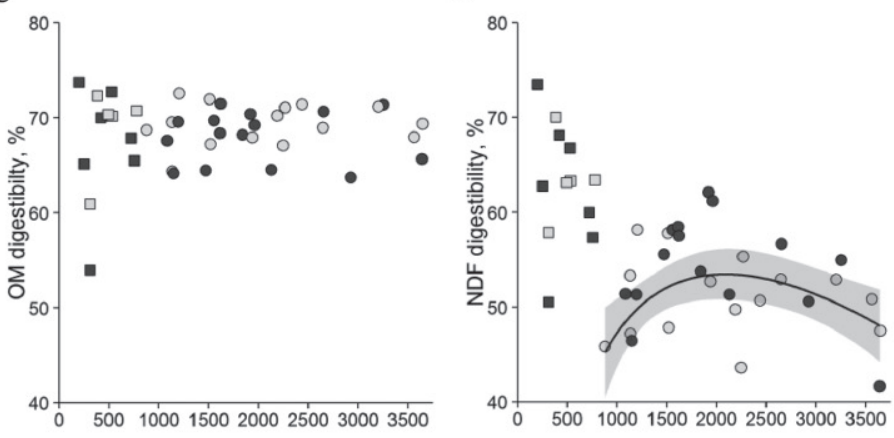

k

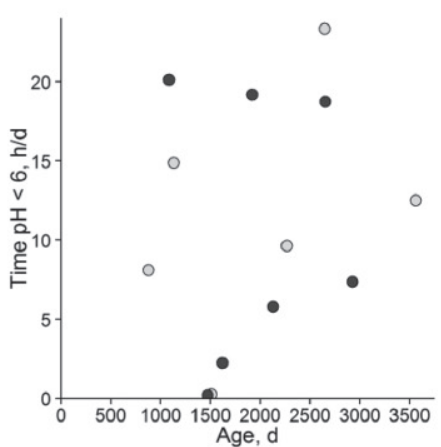

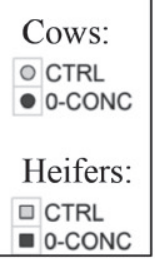

- O-CONC 
a

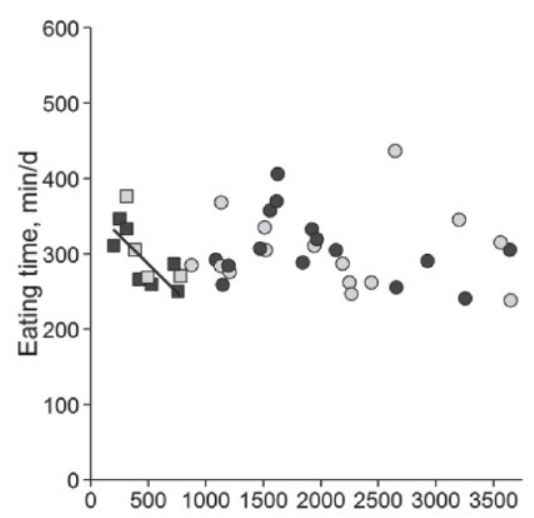

d

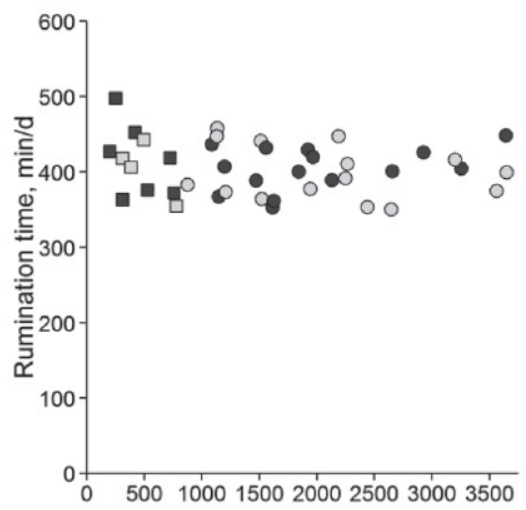

g

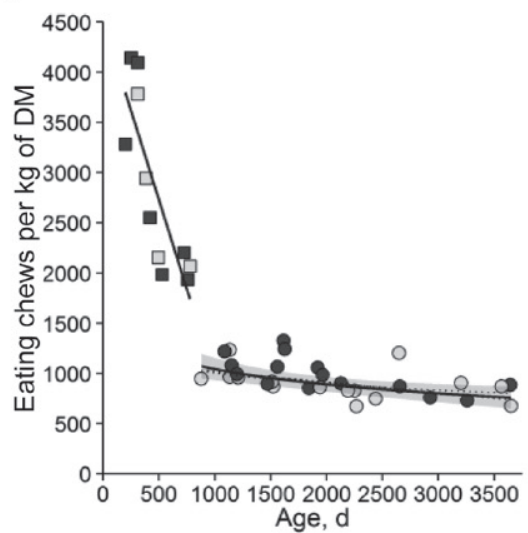

$\mathrm{b}$
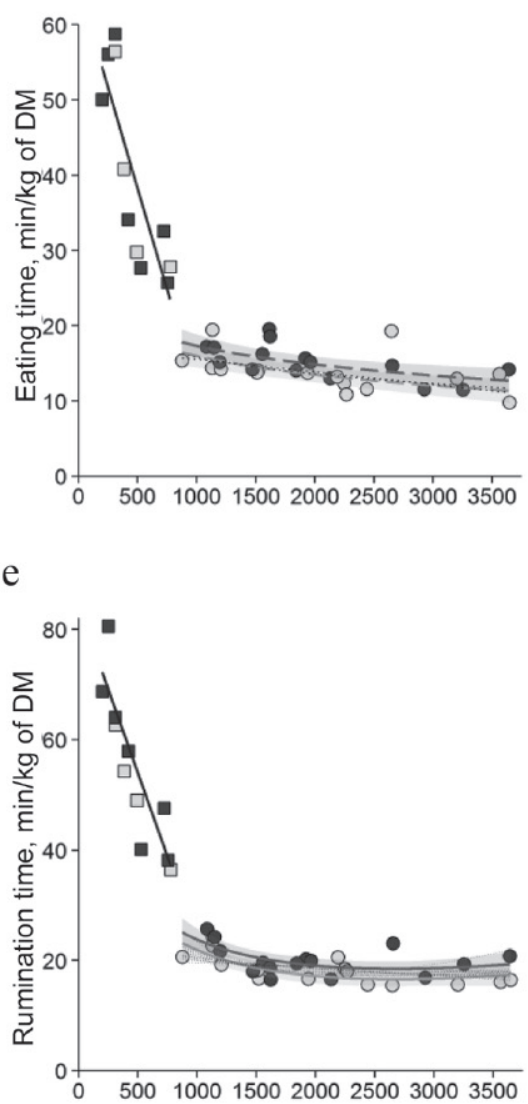

h

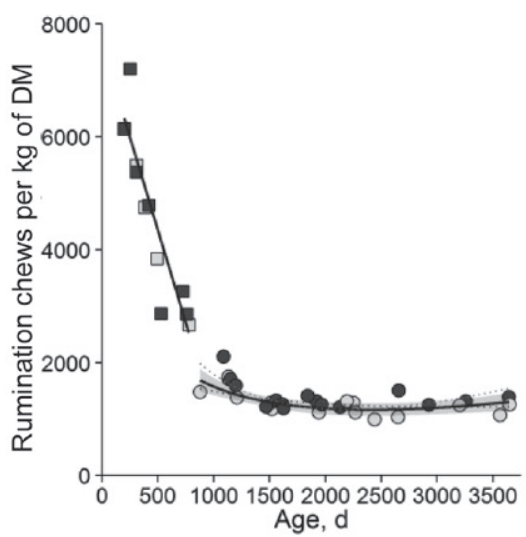

$\mathrm{C}$

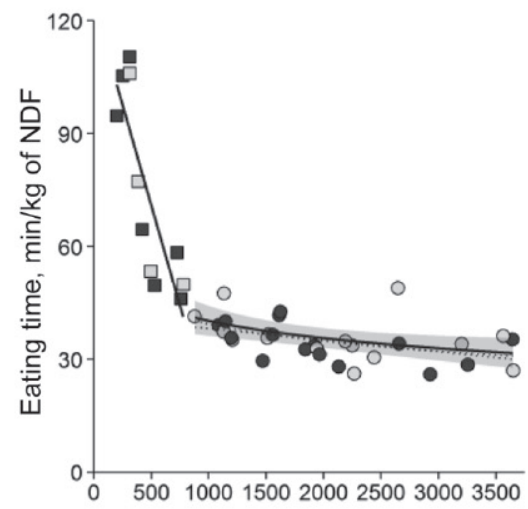

f

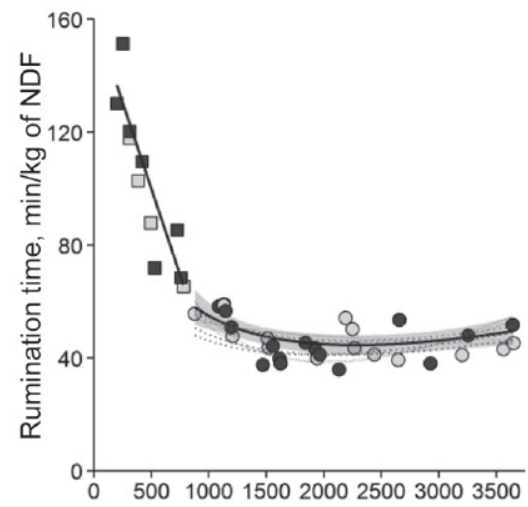

i

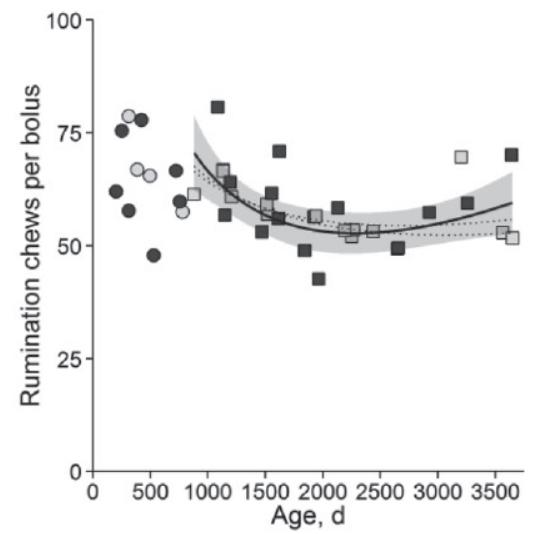

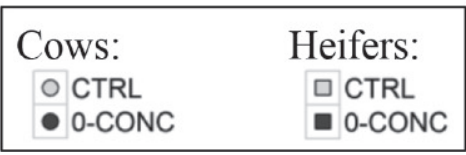

Figure 3. Observed values for cows and heifers and prediction lines for regression fits for heifers and cows (varying age but keeping BW, ECM yield, and hay proportion in forage to the respective median) of traits describing eating and rumination behavior. Symbol and line shading indicate values and prediction lines for control (CTRL; open, light gray) and zero concentrate (0-CONC; solid, dark gray) animals. Predictions were illustrated by solid lines when regression coefficients for age and feeding regimen were significant at $P<0.05$. Only one prediction line was drawn in case of $P \geq 0.10$ for feeding regimen. No prediction line was drawn in case of $P \geq 0.10$ for age. For cow regressions, shaded areas represent $95 \%$ confidence bands, and thin dotted lines represent prediction lines for regression fits of regression models within a difference $<2$ in Akaike information criterion value between the best and the respective model. The medians of heifer and cow data were significantly $(P<$ 0.001 ) different in the traits presented b, c, e, f, g, and h. 
be due to differences in mouth or bite size or intake behavior (Boudon et al., 2009). A smaller NDF intake at increasing OMI might also result from a more active sorting against NDF containing feed particles in more experienced animals. Miller-Cushon et al. (2013) offered calves either a mixed diet or diet components separately and found differences in sorting behavior later on based on their previous experience. However, the extent to which sorting experience continues or even increases during lifetime is unclear, especially considering the number of influences that contribute to diet selection in farm animals (Forbes and Kyriazakis, 1995). Leonardi et al. (2005) and Devries et al. (2011) reported even more active sorting for finer particles of primiparous compared with multiparous cows, whereas Leonardi and Armentano (2003) reported no effects of parity but emphasized the large variability in sorting between individuals. Ruminal $\mathrm{pH}$ conditions, which are also known to influence feed intake (e.g., Owens et al., 1998), did not influence OMI in the present study. The $\mathrm{pH}$ measurements of the cows equipped with boluses were within normal ranges and no age pattern was apparent. Maekawa et al. (2002b) also did not find differences in $\mathrm{pH}$ characteristics between primiparous and multiparous cows.

Along with the increasing OMI, older cows also had a longer MRT than younger cows. This is contrary to reports in literature, where greater feed intake is often associated with decreasing MRT (e.g., Allen and Mertens, 1988), but consistent with observations of increasing gut fill in older animals (Veiberg et al., 2009, Duarte et al., 2011), which had been computed in the present study. A longer MRT usually facilitates a more intensive nutrient degradation (Allen and Mertens, 1988). Still, the $\mathrm{aD}$ of $\mathrm{OM}$ did not increase with age and the $\mathrm{aD}$ of NDF even decreased from the middle of the observed age range onwards. Assuming an underlying fiber-dependent control mechanism for digesta retention (Lund et al., 2007), it could be hypothesized that the degradation of fiber is decreasing with age and older cows compensate for reduced fiber degradation by prolonged particle retention.

Heifers on the hay-only diet had, on average, approximately $7 \mathrm{~h}$ longer MRT than cows. This supports the assumption that retention time is prolonged in the presence of large amounts of fiber, but could also represent an effect of the heifers' generally lower intake. These longer MRT were also associated with a higher NDF digestibility. Owing to their lower metabolic requirements, heifers do not need to use the full capacity of their digestive system, whereas this capacity is used to its maximum in lactating cows. This allowed the heifers to consume feed with high fiber content and at the same time reach a high aD of fiber.
Daily eating times were largely constant across the observed age range. However, when related to intake, the time spent for eating per unit of intake decreased with age; this happened steeply in heifers and moderately in cows. Shorter chewing times per unit of feed in multiparous compared with primiparous cows were also observed by Dado and Allen (1994), whereas Maekawa et al. (2002b) found a trend toward longer eating times per DMI for multiparous cows. Maekawa et al. (2002b) found no differences in rumination time per unit of feed between heavier multiparous cows and lighter primiparous cows. However, rumination time per unit of intake is dependent on the level of intake if the time that cows can allocate to rumination is constant. This seems to be the case in the present study and was also reported by Bae et al. (1983). This would also explain the longer time the heifers spent eating and ruminating per unit of feed in comparison with the cows. Another reasonable explanation for the heifers' long chewing time per unit of feed intake might be a regulation of chewing activity by the level of fiber degradation. Thus, heifers on their fiber-rich diet spent more time chewing and allocated more chews per unit of feed compared with the cows. The present results also showed that the youngest and the oldest cows performed more chews per bolus and, with that, chewed faster than cows in the middle of the age range. Increasing the chewing rate (i.e., chews per unit of regurgitated matter) could be a compensatory mechanism to avoid a decline in $\mathrm{aD}$ of $\mathrm{OM}$ and fiber. The development and wear stage of the teeth, which is of importance for effective comminution of feed (PérezBarbería and Gordon, 1998), might explain part of the variation with age observed. Tooth wear is highly dependent on age (Fortelius, 1985); Pérez-Barbería and Gordon (1998) proposed alteration of chewing activity as a possible compensatory mechanism that makes up for changes in tooth effectiveness with age. Their conceptual framework shows a curvilinear relationship of chewing effectiveness with age, and thus corresponds to the present findings in the rumination traits.

\section{Effects of Feeding Regimen}

In the heifers, no differences in intake and digestion characteristics according to their feeding regimen origin were observed. This indicates that the feeding regimen effect found in the cows was actually an effect of the diet and not an effect of selecting for cows adapted to the respective feeding regimen. Such a potential effect was also weakened by using the same sires for $\mathrm{AI}$ in the breeding groups of the 2 feeding regimens.

For cows across both feeding regimens, OM and fiber intake was in the range of other studies (e.g., Maekawa et al., 2002b; Aikman et al., 2008; Zom et al., 2012). Al- 
though concentrate input was limited to a maximum of $5 \mathrm{~kg} / \mathrm{d}$ (i.e., approximately 20-25\% of DMI) for CTRL cows and totally omitted in the 0 -CONC cows, NDF contents of the diets still only ranged between 36 to $48 \%$ owing to the comparatively low fiber content of the forages. Therefore, the results from the current study are likely to be comparable with other studies where, at a similar energy density of the total diet, higher shares of concentrate were used. The OMI, when corrected for BW and ECM yield, was only numerically lower in 0-CONC cows than in CTRL cows, thus confirming that cows are able to compensate to a certain degree a reduced concentrate intake by increasing forage consumption (Leiber et al., 2015). Higher proportions of fiber in 0-CONC diets, which limit intake due to the physical properties of fiber (Allen, 2000; Zom et al., 2012), additionally explain a numerically lower OMI in 0 -CONC cows. No clear relationship between the feeding regimen and the daily eating and rumination times was found. In contrast, Robinson and McQueen (1997) as well as Maekawa et al. (2002a) found that lower concentrate proportions in dairy cow diets prolonged daily rumination and eating times. In relation to DM and NDF intake, the 0-CONC cows spent the same time for eating. This again indicates that cows allocated a certain amount of time to eating (here irrespective of diet composition). The $0-\mathrm{CONC}$ cows spent more time per unit of DMI to ruminate, presumably because it takes more effort to comminute the greater amounts of fiber in the diet. In spite of that, no other rumination trait showed a significant feeding regimen difference. A possible reason for this could be a greater chewing ability or better adapted fiber-degrading rumen microbes in cows that are used to consume only forage. A detrimental effect of concentrate on fiber-degrading microbes due to shifts in $\mathrm{pH}$ levels is also well known (Mulligan et al., 2002). However, ruminal $\mathrm{pH}$ remained well above critical thresholds in the CTRL cows, indicating that these cows were not deficient in effective fiber (Mertens, 1997). Additionally, greater shares of grass pellets were used in the 0-CONC diet to partly replace the concentrate. Due to their short particle structure, these pellets are more similar to concentrate than other forage in terms of physical properties. Accordingly, Woodford and Murphy (1988) found less rumination when alfalfa haylage was replaced with alfalfa pellets.

\section{CONCLUSIONS}

In the present study, significant age effects were noted in feeding, ruminating, and digestion characteristics in dairy cattle. Older cows were able to ingest more yet maintained digestion efficiency to a large extent and seemed to adapt their eating and ruminating activity to their ability of fiber degradation. Additionally, older cows appeared to select against fiber-containing particles. The reasons for several of these changes with age still need to be explored in more detail, but could include learning from experiences in feeding and ruminating behavior. There might also be anatomic changes taking place, such as the changing morphology of the teeth over time. The assumption that age effects could be differently exhibited with different diet types was rejected given the diets investigated. In general, diet effects of the 2 feeding regimens on traits describing intake and digestion were less pronounced than expected, possibly because forage quality was very high in the present experiment. Overall, the current results support efforts to increase the length of the productive life in dairy cows as, at least in the age range investigated, no negative developments with age were found.

\section{ACKNOWLEDGMENTS}

The authors are grateful for the support of the institutions and persons involved in the experiment: Plantahof (A. Accola, D. Balestra, C. Brandenburger, K. Freuler, J. Jenewein, P. Küchler), ETH Zurich (S. Marquardt, R. Messikommer), the lab teams at ETH and IZW (C. Kunz, M. Mergani, P. Stirnemann, E. Wenk, H. Barleben). Special thanks go to M. Kalisch (ETH Zurich) and M. Dolezal (University of Veterinary Medicine, Vienna) for their assistance in the statistical analysis. The project was supported by the Mercator Research Program of the ETH Zurich World Food System Center.

\section{REFERENCES}

Agroscope. 2015. Feeding Recommendations and Nutrient Tables for Ruminants (in German). Online Version. Accessed July 23, 2015. http://www.agroscope.admin.ch/futtermitteldatenbank/04834/.

Aikman, P. C., C. K. Reynolds, and D. E. Beever. 2008. Diet digestibility, rate of passage, and eating and rumination behavior of Jersey and Holstein cows. J. Dairy Sci. 91:1103-1114.

Akaike, H. 1974. A new look at the statistical model identification. IEEE Trans. Automat. Contr. 19:716-723.

Allen, M. S. 2000. Effects of diet on short-term regulation of feed intake by lactating dairy cattle. J. Dairy Sci. 83:1598-1624.

Allen, M. S., and D. R. Mertens. 1988. Evaluating constraints on fiber digestion by rumen microbes. J. Nutr. 118:261-270.

Allison, C. D. 1985. Factors affecting forage intake by range ruminants: A review. J. Range Manage. 38:305-311.

AOAC International. 1995. Official Methods of Analysis. AOAC International, Arlington, VA.

Azizi, O., O. Kaufmann, and L. Hasselmann. 2009. Relationship between feeding behaviour and feed intake of dairy cows depending on their parity and milk yield. Livest. Sci. 122:156-161.

Bae, D. H., J. G. Welch, and B. E. Gilman. 1983. Mastication and rumination in relation to body size of cattle. J. Dairy Sci. 66:21372141.

Boudon, A., J.-L. Peyraud, P. Faverdin, R. Delagarde, L. Delaby, and A. V. Chaves. 2009. Effect of rumen fill on intake of fresh perennial 
ryegrass in young and mature dairy cows grazing or zero-grazing fresh perennial ryegrass. Animal 3:1706-1720.

Braun, U., L. Trösch, F. Nydegger, and M. Hässig. 2013. Evaluation of eating and rumination behaviour in cows using a noseband pressure sensor. BMC Vet. Res. 9:164.

Calcagno, V. 2013. glmulti: Model selection and multimodel inference made easy. Accessed Feb. 12, 2016. http://CRAN.R-project.org/ package $=$ glmulti.

Capper, J. L., and D. E. Bauman. 2013. The role of productivity in improving the environmental sustainability of ruminant production systems. Annu. Rev. Anim. Biosci. 1:469-489.

Dado, R. G., and M. S. Allen. 1994. Variation in and relationships among feeding, chewing, and drinking variables for lactating dairy cows. J. Dairy Sci. 77:132-144.

Devries, T. J., L. Holtshausen, M. Oba, and K. A. Beauchemin. 2011. Effect of parity and stage of lactation on feed sorting behavior of lactating dairy cows. J. Dairy Sci. 94:4039-4045.

Duarte, A., D. R. McCullough, and F. W. Weckerly. 2011. Does rumen-reticulum capacity correlate with body size or age in blacktailed deer? Eur. J. Wildl. Res. 57:1131-1136.

Fall, N., K. Forslund, and U. Emanuelson. 2008. Reproductive performance, general health, and longevity of dairy cows at a Swedish research farm with both organic and conventional production. Livest. Sci. 118:11-19.

Flachowsky, G., and W. Brade. 2007. Potenziale zur Reduzierung der Methanemissionen bei Wiederkäuern. Zuechtungskunde 79:417465. (Reduction potentials for methane emissions from ruminants; in German).

Forbes, J. M., and I. Kyriazakis. 1995. Food preferences in farm animals: Why don't they always choose wisely? Proc. Nutr. Soc. 54:429-440.

Fortelius, M. 1985. Ungulate cheek teeth: Developmental, functional, and evolutionary interactions. Acta Zool. Fenn. 180:1-76.

Fox, J. 2003. Effect displays in R for generalised linear models. J. Stat. Softw. 8:1-27.

Gasteiner, J., T. Guggenberger, J. Häusler, and A. Steinwidder. 2012. Continuous and long-term measurement of reticuloruminal $\mathrm{pH}$ in grazing dairy cows by an indwelling and wireless data transmitting unit. Vet. Med. Int. 2012:236956. http://dx.doi. org $/ 10.1155 / 2012 / 236956$.

Graham, N. McC. 1980. Variation in energy and nitrogen utilization by sheep between weaning and maturity. Aust. J. Agric. Res. 31:335-345.

Grandl, F., S. L. Amelchanka, M. Furger, M. Clauss, J. O. Zeitz, M. Kreuzer, and A. Schwarm. 2016. Biological implications of longevity in dairy cows: 2. Changes in methane emissions and efficiency with age. J. Dairy Sci. 99:3472-3485. http://dx.doi.org/10.3168/ jds.2015-10262.

Hadley, G. L., C. A. Wolf, and S. B. Harsh. 2006. Dairy cattle culling patterns, explanations, and implications. J. Dairy Sci. 89:22862296.

Hare, E., H. D. Norman, and J. R. Wright. 2006a. Survival rates and productive herd life of dairy cattle in the United States. J. Dairy Sci. 89:3713-3720.

Hare, E., H. D. Norman, and J. R. Wright. 2006b. Trends in calving ages and calving intervals for dairy cattle breeds in the United States. J. Dairy Sci. 89:365-370.

Hayirli, A., R. R. Grummer, E. V. Nordheim, and P. M. Crump. 2002. Animal and dietary factors affecting feed intake during the prefresh transition period in Holsteins. J. Dairy Sci. 85:3430-3443.

Holleman, D. F., and R. G. White. 1989. Determination of digesta fil and passage rate from nonabsorbed particulate phase markers using the single dosing method. Can. J. Zool. 67:488-494.

Jensen, L. M., N. I. Nielsen, E. Nadeau, B. Markussen, and P. Nørgaard. 2015. Evaluation of five models predicting feed intake by dairy cows fed total mixed rations. Livest. Sci. 176:91-103.

Keene, B. E., K. F. Knowlton, M. L. McGilliard, L. A. Lawrence, S. M. Nickols-Richardson, J. H. Wilson, A. M. Rutledge, L. R. Mc-
Dowell, and M. E. Van Amburgh. 2004. Measures of bone mineral content in mature dairy cows. J. Dairy Sci. 87:3816-3825.

Kiefer, L., F. Menzel, and E. Bahrs. 2014. The effect of feed demand on greenhouse gas emissions and farm profitability for organic and conventional dairy farms. J. Dairy Sci. 97:7564-7574.

Knaus, W. 2009. Dairy cows trapped between performance demands and adaptability. J. Sci. Food Agric. 89:1107-1114.

Leiber, F., K. Dorn, J. K. Probst, A. Isensee, N. Ackermann, A. Kuhn, and A. Spengler Neff. 2015. Concentrate reduction and sequential roughage offer to dairy cows: effects on milk protein yield, protein efficiency and milk quality. J. Dairy Res. 82:272-278.

Leonardi, C., and L. E. Armentano. 2003. Effect of quantity, quality, and length of alfalfa hay on selective consumption by dairy cows. J. Dairy Sci. 86:557-564.

Leonardi, C., K. J. Shinners, and L. E. Armentano. 2005. Effect of different dietary geometric mean particle length and particle size distribution of oat silage on feeding behavior and productive performance of dairy cattle. J. Dairy Sci. 88:698-710.

Lund, P., M. R. Weisbjerg, and T. Hvelplund. 2007. Digestible NDF is selectively retained in the rumen of dairy cows compared to indigestible NDF. Anim. Feed Sci. Technol. 134:1-17.

Maekawa, M., K. A. Beauchemin, and D. A. Christensen. 2002a. Effect of concentrate level and feeding management on chewing activities, saliva production, and ruminal $\mathrm{pH}$ of lactating dairy cows. J. Dairy Sci. 85:1165-1175.

Maekawa, M., K. A. Beauchemin, and D. A. Christensen. 2002b. Chewing activity, saliva production, and ruminal $\mathrm{pH}$ of primiparous and multiparous lactating dairy cows. J. Dairy Sci. 85:1176-1182.

Mertens, D. R. 1997. Creating a system for meeting the fiber requirements of dairy cows. J. Dairy Sci. 80:1463-1481.

Miglior, F., B. L. Muir, and B. J. Van Doormaal. 2005. Selection indices in Holstein cattle of various countries. J. Dairy Sci. 88:12551263.

Miller-Cushon, E. K., R. Bergeron, K. E. Leslie, G. J. Mason, and T. J. DeVries. 2013. Effect of early exposure to different feed presentations on feed sorting of dairy calves. J. Dairy Sci. 96:4624-4633.

Müller, D. W. H., D. Codron, C. Meloro, A. Munn, A. Schwarm, J. Hummel, and M. Clauss. 2013. Assessing the Jarman-Bell Principle: scaling of intake, digestibility, retention time and gut fill with body mass in mammalian herbivores. Comp. Biochem. Physiol. A Mol. Integr. Physiol. 164:129-140.

Mulligan, F. J., P. J. Caffrey, M. Rath, J. J. Callan, P. O. Brophy, and F. P. O'Mara. 2002. An investigation of feeding level effects on digestibility in cattle for diets based on grass silage and high fibre concentrates at two forage:concentrate ratios. Livest. Prod. Sci. $77: 311-323$.

Oltjen, J. W., and J. L. Beckett. 1996. Role of ruminant livestock in sustainable agricultural systems. J. Anim. Sci. 74:1406-1409.

Owens, F. N., D. S. Secrist, W. J. Hill, and D. R. Gill. 1998. Acidosis in cattle: A review. J. Anim. Sci. 76:275-286.

Pérez-Barbería, F. J., and I. J. Gordon. 1998. Factors affecting food comminution during chewing in ruminants: A review. Biol. J. Linn. Soc. Lond. 63:233-256.

Pinedo, P. J., A. De Vries, and D. W. Webb. 2010. Dynamics of culling risk with disposal codes reported by Dairy Herd Improvement dairy herds. J. Dairy Sci. 93:2250-2261.

Prendiville, R., K. M. Pierce, and F. Buckley. 2009. An evaluation of production efficiencies among lactating Holstein-Friesian, Jersey, and Jersey $\times$ Holstein-Friesian cows at pasture. J. Dairy Sci. 92:6176-6185.

R Core Team. 2015. R: A language and environment for statistical computing. R Foundation for Statistical Computing, Vienna, Austria.

Riaz, M. Q., K.-H. Südekum, M. Clauss, and A. Jayanegara. 2014. Voluntary feed intake and digestibility of four domestic ruminant species as influenced by dietary constituents: A meta-analysis. Livest. Sci. $162: 76-85$. 
Robinson, P. H., and R. E. McQueen. 1997. Influence of level of concentrate allocation and fermentability of forage fiber on chewing behavior and production of dairy cows. J. Dairy Sci. 80:681-691.

Rohde, H., K. F. Stock, H. Hamann, F. Reinhardt, R. Reents, W. Brade, and O. Distl. 2009. Analysen zu Lebensleistung und Nutzungsdauer bei deutschen Holstein Kühen. Zuechtungskunde 81:42-45. (Analysis of lifetime performance and length of productive life from German Holstein cows; in German).

Symonds, M. R. E., and A. Moussalli. 2011. A brief guide to model selection, multimodel inference and model averaging in behavioural ecology using Akaike's information criterion. Behav. Ecol. Sociobiol. 63:13-21.

Thielemans, M.-F., E. François, C. Bodart, and A. Thewis. 1978. Mesure du transit gastrointestinal chez le porc à l'aide des radiolanthanides. Comparaison avec le mouton. Ann. Biol. Anim. Biochim. Biophys. 18:237-247. (Gastrointestinal transit in the pig: measurement using radioactive lanthanides and comparison with sheep; in French).

Udén, P., P. E. Colucci, and P. J. Van Soest. 1980. Investigation of chromium, cerium and cobalt as markers in digesta rates of passage studies. J. Sci. Food Agric. 31:625-632
Van Soest, P. J., J. B. Robertson, and B. A. Lewis. 1991. Methods for dietary fiber, neutral detergent fiber, and nonstarch polysaccharides in relation to animal nutrition. J. Dairy Sci. 74:3583-3597.

Veiberg, V., A. Mysterud, R. J. Irvine, W. Sørmo, and R. Langvatn. 2009. Increased mass of reticulo-rumen tissue and contents with advancing age in Svalbard reindeer. J. Zool. (Lond.) 278:15-23.

Wathes, D. C., Z. Cheng, N. Bourne, V. J. Taylor, M. P. Coffey, and S. Brotherstone. 2007. Differences between primiparous and multiparous dairy cows in the inter-relationships between metabolic traits, milk yield and body condition score in the periparturient period. Domest. Anim. Endocrinol. 33:203-225.

Woodford, S. T., and M. R. Murphy. 1988. Effect of forage physical form on chewing activity, dry matter intake, and rumen function of dairy cows in early lactation. J. Dairy Sci. 71:674-686.

Zom, R. L. G., G. André, and A. M. van Vuuren. 2012. Development of a model for the prediction of feed intake by dairy cows: 1 . Prediction of feed intake. Livest. Sci. 143:43-57. 